\title{
Pearls \& Oy-sters: Alternating hemiplegia of childhood mimics focal epilepsy and paroxysmal dyskinesia in infancy
}

Monica B. Dhakar, MD, MS, and Nigel S. Bamford, MD

Neurology ${ }^{\circledR}$ 2018;91:47-49. doi:10.1212/WNL.0000000000005745

\section{Pearls}

- Paroxysmal dyskinesia is often seen in patients with alternating hemiplegia of childhood (AHC).

- Paroxysmal dyskinesia may be the first presentation of AHC and can precede the hemiplegic attacks by several months.

- These dystonic movements can mimic focal seizures, which are also seen in $40 \%$ to $50 \%$ of patients with AHC.

\section{Oy-sters}

- AHC should be considered in infants presenting with paroxysmal dyskinesia.

- Paroxysmal dyskinesia can often be misdiagnosed as seizures, and some patients may respond to anticonvulsant treatment.

- Video EEG is helpful in distinguishing the underlying diagnosis, particularly in AHC in which seizures and paroxysmal dyskinesias may coexist.

\section{Case report}

A 4-month-old boy presented with new-onset paroxysmal spells that began at 10 weeks of age. The initial events consisted of forced head and eye deviation to the left, with a left-beating horizontal nystagmus lasting approximately 5 minutes. He was the product of a full-term pregnancy without complications. He fed well and was achieving all of his early developmental milestones. Family history was unremarkable for neurologic disease. The child's initial examination revealed mild central hypotonia, but was normal otherwise. A routine sleep-awake EEG was normal but failed to capture an episode. Similar spells occurred weekly, but he had no unusual movements during sleep. During some events, he seemed less interactive with his surroundings and on occasion experienced mild respiratory distress and perioral cyanosis. A presumptive diagnosis of seizures was made, and he was treated with increasing doses of levetiracetam. Despite treatment, the events increased in frequency and duration, some lasting 20 minutes with associated stiffening of either arm, head deviation, and tonic gaze preference. The lack of clinical response to anticonvulsant medication raised the suspicion for nonepileptic attacks (seizure mimics) and he was admitted to the hospital for further evaluation. Brain MRI, serum electrolytes, liver function tests, lactate, plasma amino acids, and urine organic acids were unremarkable. CSF was acellular and revealed normal protein and glucose levels. Neurotransmitter metabolites indicated a slightly low homovanillic acid of $429 \mathrm{nmol} / \mathrm{L}$ (range: 450-1,132 nmol/L). 5-Hydroxyindoleacetic acid, 3-Omethyldopa, neopterin, tetrahydrobiopterin, and 5-methyltetrahydrofolate were normal. Video EEG monitoring captured a paroxysmal event, characterized by head and gaze deviation to the right side, stiffening of the right arm, and poor interaction with his surroundings (video). The event was uninterrupted by physical and verbal stimulation and was terminated by sleep. The EEG
Correspondence

Dr. Dhakar

mdhakar@emory.edu

$\checkmark$ Video 
recording revealed normal background for age without any abnormal electrographic changes, consistent with paroxysmal dyskinesia.

The differential diagnosis of paroxysmal dyskinesia during infancy encompasses a variety of genetic and metabolic causes (table). A detailed investigational panel evaluating these etiologies was sent. Genetic analysis demonstrated a de novo heterozygote mutation in ATP1A3, a gene associated with $75 \%$ of cases of sporadic AHC, confirming the diagnosis. ${ }^{1,2}$ By 8 months of age, the paroxysmal dyskinesias abated and he developed classic attacks of alternating hemiplegia overlying a baseline global developmental delay. Benzodiazepines and acetazolamide provided

Table Differential diagnosis of paroxysmal dyskinesia in childhood

Genetic

Dopa-responsive dystonia (GTP cyclohydrolase 1, tyrosine hydroxylase, sepiapterin reductase)

Alternating hemiplegia of childhood (ATP1A3)

\begin{tabular}{l}
\hline Paroxysmal kinesigenic dyskinesia (PRRT2) \\
\hline $\begin{array}{l}\text { Primary paroxysmal nonkinesigenic dyskinesia (mapped to chromosome } \\
\text { 2q31-36) }\end{array}$ \\
\hline Paroxysmal exercise-induced dyskinesia (unknown)
\end{tabular}

Paroxysmal exercise-induced dyskinesia (unknown)

Glut-1 transporter (SLC2A1)

Primary torsion dystonia (DYT1)

Myoclonus dystonia (SGCE)

Infantile parkinsonism dystonia (SLC6A3)

Huntington disease

Metabolic disorders

Glutaric aciduria type $1(G C D H)$

Mitochondrial disease (many)

Infantile-epileptic dyskinetic encephalopathy (Xp21.3)

Drugs/toxins

Hypoxic-ischemic injury, acute or late manifestation of

Bilirubin deposition in the basal ganglia (kernicterus)

Copper (Wilson) and iron deposition (PKAN) and others

Carbamazepine, antihistamines, antipsychotics, antiemetics, and other drugs

Methanol and carbon monoxide (delayed symptoms are common)

Mimics

Transient paroxysmal dystonia of infancy

Infantile spasms and focal epilepsy

Sandifer syndrome with gastroesophageal reflux

Normal (funky) baby movements

Abbreviation: PKAN = pantothenate kinase-associated neurodegeneration. some intermittent relief, while oxcarbazepine, topiramate, and flunarizine had little effect. A ketogenic diet was initiated, and at the time of this submission, shows promise in reducing the number of attacks. Follow-up EEG and MRI studies remained normal.

\section{Discussion}

AHC is a rare disorder with an incidence of 1 in 1 million individuals. ${ }^{2}$ Most cases are sporadic; however, in the rare familial cases, the inheritance is autosomal dominant. ${ }^{3}$ The most common mutation involves the ATP1A 3 gene. ${ }^{1}$ ATP $1 \mathrm{~A} 3$ is a part of the $\alpha$ subunit of $\mathrm{Na}^{+} / \mathrm{K}^{+}$adenosine triphosphatase (ATPase) protein, which is responsible for normal transport of ions across neuronal membrane. The mutation reduces the activity of $\mathrm{Na}^{+} / \mathrm{K}^{+}$ATPase without affecting the protein levels, resulting in impaired functioning. Mutation in the ATP1A3 gene is also associated with 2 other movement disorders: rapidonset dystonia-parkinsonism and the syndrome of cerebellar ataxia, areflexia, pes cavus, optic atrophy, and sensorineural hearing loss (CAPOS). ${ }^{4}$

The spectrum of clinical symptoms of AHC is broad and consists of episodic hemiplegia or quadriplegia, dystonic posturing, choreoathetoid movements, abnormal ocular movements, developmental delay, and progressive cognitive impairment. ${ }^{5}$ The first attack usually occurs between 3.5 and 7 months of age, although symptoms can be seen as early as the second day of life. ${ }^{5,6}$ The diagnostic criteria for AHC have been defined below. ${ }^{5}$ Of these, criteria $1,2,3$, and 7 are required for a definitive diagnosis of "typical" AHC.

1. Onset of paroxysmal events before 18 months of age

2. Repeated attacks of hemiplegia with attacks on right and left side of the body

3. Episodes of bilateral hemiplegia or quadriplegia starting either as generalization of hemiplegia attack or bilateral from the onset

4. Other paroxysmal events, such as tonic/dystonic attacks, nystagmus, strabismus; dyspnea or autonomic disturbances during the hemiplegia attack or in isolation

5. Disappearance of the symptoms with sleep followed by recurrence upon awakening

6. Evidence of developmental delay, cognitive impairment

7. Not attributable to any other cause

Hemiplegic attacks as the first sign of AHC is seen in only onethird of cases, whereas in the remainder, it is often followed by dystonic episodes or ocular abnormalities such as nystagmus. In fact, the incidence of dystonic episodes preceding the hemiplegic attacks is highest during the first 3 months of life. ${ }^{6}$ In our patient, the dystonic attacks preceded the hemiplegic attacks by 4 months. He was also noted to have transient abnormal ocular movements. Because of the variability in presenting symptoms, the diagnosis is challenging and can often be delayed or misdiagnosed as epilepsy. Although tonic gaze is a common 
presenting symptom of AHC, ${ }^{6,7}$ it is a hallmark of focal seizures and presents a diagnostic challenge that is aided by video EEG. Co-occurrence or late occurrence of epileptic seizures with autonomic features is seen in $40 \%$ to $53 \%$ of patients with AHC. These patients often have autonomic dysfunction causing flushing, sweating, mydriasis, and sometimes respiratory distress with cyanosis, again mimicking seizures. However, features of bilateral episodic nystagmus or gaze deviation and periods of intermittent and alternating stiffening of extremities lasting minutes to hours with preserved responsiveness differentiate dystonic spells from seizures and should prompt the investigations toward this condition.

Treatment of AHC is challenging. The spells often abate with sleep, and efforts to identify and reduce triggers such as unexpected stimuli and stress are required. Treatment of AHC is symptomatic and is directed toward reducing the severity and duration of the paroxysmal spells. Anticonvulsant and calcium channel blockers are often used with variable success. ${ }^{2} \mathrm{Al}$ ternatively, drugs such as acetazolamide or the ketogenic diet that may modify cellular $\mathrm{pH}, \gamma$-aminobutyric acid, or metabolic pathways have been attempted. ${ }^{8}$ Such treatments may modify the neuronal membrane potential or the probability of neurotransmitter release but the mechanism is indirect and their efficacy remains unproven. The severity of the disease appears to be related to the genetic mutation, and whether treatment improves developmental outcome in addition to the frequency of the spells remains unclear.

\section{Author contributions}

Dr. Monica B. Dhakar: study concept, design, data acquisition, and drafting the manuscript. Dr. Nigel Bamford: study concept, design, intellectual content, and revising the manuscript.

\section{Study funding}

No targeted funding reported.

\section{Disclosure}

The authors report no disclosures relevant to the manuscript. Go to Neurology.org/N for full disclosures.

\section{References}

1. Heinzen EL, Swoboda KJ, Hitomi Y, et al. De novo mutations in ATP1A3 cause alternating hemiplegia of childhood. Nat Genet 2012;44:1030-1034.

2. Neville BG, Ninan M. The treatment and management of alternating hemiplegia of childhood. Dev Med Child Neurol 2007;49:777-780.

3. Mikati MA, Maguire H, Barlow CF, et al. A syndrome of autosomal dominant alternating hemiplegia: clinical presentation mimicking intractable epilepsy; chromosomal studies; and physiologic investigations. Neurology 1992;42:2251-2257.

4. Brashear A, Sweadner KJ, Cook JF, Swoboda KJ, Ozelius L. ATP1A3-related neurologic disorders. In: Adam MP, Ardinger HH, Pagon RA, et al, editors. GeneReviews. Seattle: University of Washington; 1993.

5. Panagiotakaki E, Gobbi G, Neville B, et al. Evidence of a non-progressive course of alternating hemiplegia of childhood: study of a large cohort of children and adults. Brain 2010; 133:3598-3610

6. Sweney MT, Silver K, Gerard-Blanluet M, et al. Alternating hemiplegia of childhood: early characteristics and evolution of a neurodevelopmental syndrome. Pediatrics 2009; 123:e534-e541.

7. Mikati MA, Kramer U, Zupanc ML, Shanahan RJ. Alternating hemiplegia of childhood: clinical manifestations and long-term outcome. Pediatr Neurol 2000;23:134-141.

8. Roubergue A, Philibert B, Gautier A, et al. Excellent response to a ketogenic diet in a patient with alternating hemiplegia of childhood. JIMD Rep 2015;15:7-12.

\section{Did You Know...}

... you can browse by subspecialty topics on Neurology.org?

Go to: Neurology.org and click on "Topics" in the top navigation bar.

\section{Neurology ${ }^{\circledR}$ Online CME Program}

Earn CME while reading Neurology. This program is available only to online Neurology subscribers. Read the articles marked CME, go to Neurology.org, and click on CME. This will provide all of the information necessary to get started. The American Academy of Neurology (AAN) is accredited by the Accreditation Council for Continuing Medical Education (ACCME) to sponsor continuing medical education for physicians. Neurology is planned and produced in accordance with the ACCME Essentials. For more information, contact AAN Member Services at 800-879-1960. 


\section{Neurology}

\section{Pearls \& Oy-sters: Alternating hemiplegia of childhood mimics focal epilepsy and paroxysmal dyskinesia in infancy}

Monica B. Dhakar and Nigel S. Bamford

Neurology 2018;91;47-49

DOI 10.1212/WNL.0000000000005745

\section{This information is current as of July 2, 2018}

\section{Updated Information \&} Services

References

Subspecialty Collections

Permissions \& Licensing

Reprints including high resolution figures, can be found at: http://n.neurology.org/content/91/1/47.full

This article cites 7 articles, 1 of which you can access for free at: http://n.neurology.org/content/91/1/47.full\#ref-list-1

This article, along with others on similar topics, appears in the following collection(s): All Epilepsy/Seizures http://n.neurology.org/cgi/collection/all_epilepsy_seizures

Information about reproducing this article in parts (figures,tables) or in its entirety can be found online at:

http://www.neurology.org/about/about_the_journal\#permissions

Information about ordering reprints can be found online:

http://n.neurology.org/subscribers/advertise

Neurology ${ }^{\circledR}$ is the official journal of the American Academy of Neurology. Published continuously since 1951, it is now a weekly with 48 issues per year. Copyright () 2018 American Academy of Neurology. All rights reserved. Print ISSN: 0028-3878. Online ISSN: 1526-632X.

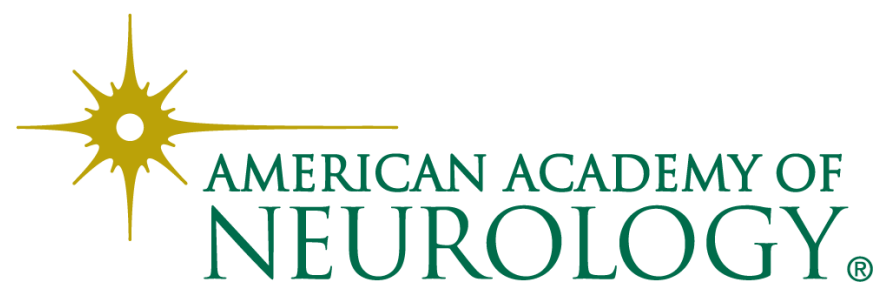

